\title{
BIOETHICS
}

RESEARCH LIBRARY

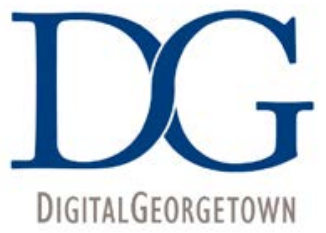

at GEORGETOWN UNIVERSITY

Bioethics Research Library at Georgetown University

https://repository.library.georgetown.edu/handle/10822/503786

The author made this article openly available online at the

Georgetown University Institutional Repository.

The Bioethics Research Library is collaborating with Georgetown's University Library to digitize, preserve and extend the history of Bioethics.

Please tell us how this access affects you. Your story matters.

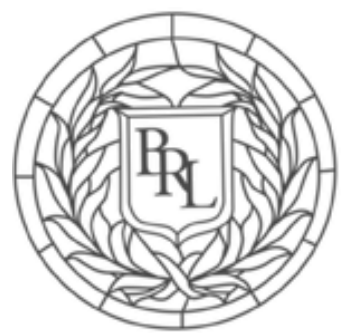

Visit us at https://bioethics.georgetown.edu/.

Copyright (C) 1995 The Johns Hopkins University Press. This article first appeared in Kennedy Institute of Ethics Journal, Volume 5 Issue 3; September 1995, pages 199-218.

Collection Permanent Link: hdl.handle.net/10822/503786

This material is made available online with the permission of the author, and in accordance with publisher policies. No further reproduction or distribution of this copy is permitted by electronic transmission or any other means. 


\section{Resolving Conflicts Among Principles: Ranking, Balancing, and Specifying}

ABSTRACT. While much attention has been given to the use of principles in biomedical ethics and increasing attention is given to alternative theoretical approaches, relatively little attention has been devoted to the critical task of how one resolves conflicts among competing principles. After summarizing the system of principles and some problems in conceptualizing the principles, several strategies for reconciling conflicts among principles are examined including the use of single-principle theories (pure libertarianism, pure utilitarianism, and pure Hippocratism), balancing theories, conflicting appeals theories, and lexical ordering. Then a mixed strategy is proposed in which consequentialist principles are balanced between themselves as are nonconsequentialist principles, after which the result of balancing the nonconsequentialist principles is lexically ranked over the result of balancing the consequentialist ones. Finally, strategies involving specifying and rule generation are discussed concluding that most current specification and rule-generating theories must involve some degree of lexical ordering of principles.

$\mathrm{I}$

N THIS ARTICLE I will work primarily within principlist approaches to bioethics to look at the differences among principlists and are highly generalized right-making characteristics of actions or rules that govern actions. Affirming a moral principle is the same as claiming that insofar as an action or rule contains the characteristic of the principle, the action is prima facie morally right. Principles may come into conflict in various bioethical systems. The question of what should happen when these conflicts occur remains an important problem in bioethics theory. My objective is to examine how different ethical theories handle the problem of conflicting principles. 
The discussion should begin with a distinction between two types of principles. (1) Some principles, such as beneficence and nonmaleficence, identify the maximizing of good consequences and/or the minimizing of bad ones as right-making characteristics of actions. I shall call these "consequence-maximizing principles." (2) Other principles have nothing to do with maximizing consequences. They focus instead on the formal structure of the action or rule: an act of truth-telling (which is referred to as the principle of veracity), an act of promise keeping (fidelity), an act of killing (avoidance of killing), or an act of respecting the autonomous choices of others (autonomy). Some such principles focus on the pattern of the distribution of benefits and harms (justice). All of these nonconsequentialist principles are related to formalism or deontological ethics.

\section{THE SYSTEM OF PRINCIPLES}

\section{Utility (The Consequence-Maximizing Principles)}

Structurally the simplest principle-based system is utilitarianism. Utilitarian theory holds that an act or rule is right insofar as it produces consequences that are as good or better than any alternative act or rule. There are many varieties of consequence-maximizing principles.

\section{Hippocratic vs. Social Utility}

Social utility considers the benefits and harms for all parties affected by an action or rule. Some forms of social utilitarianism limit the relevant benefits and harms to those experienced by human beings or by persons. Others include other animal species or, potentially, any entity that can experience benefit and harm. By contrast Hippocratic utility limits relevant benefits and harms to the individual patient with whom one is interacting. This form of consequentialism is particularly fashionable among physicians and others oriented to biomedical ethics.

Choosing which benefits and harms are morally relevant is a problem that cannot be solved simply by adopting utilitarian reasoning. It is an open question whether all benefits and harms count equally, whether the exclusive focus of a health-care giver, for example, should be on health benefits for the patient or whether the care giver's attention should be broadened to other benefits as well. The principle of utility itself leaves such questions open. Particular theories of axiology-i.e., value theory or the theory of what counts as the good-help to address some of these 
issues as well as the issues of how to quantify the amount of good or harm that is done by alternative courses of action.

\section{Two Major Consequence-Maximizing Principles}

The two major consequence-maximizing principles are those of beneficence and nonmaleficence: the notions that actions tend to be morally right-making insofar as they produce good consequences and avoid evil ones. Sometimes the two notions are combined in some fashion in which case one may speak simply of the principle of utility.

\section{Ways of Combining Benefits and Harms}

There are many different ways of combining benefits and harms, no one of which is obviously correct. Thus even among confirmed utilitarians there may be significant internal disputes, not only on the issue of whose benefits and harms count and whether to include only health benefits or other benefits as well, but also over how to combine different benefits and harms.

Benthamites, for example, sum the net consequences of an action by adding the benefits of each possible course of action for each person, subtracting the harms, and then summing across all affected persons. Other versions may strive to maximize benefit/harm ratios. There are important substantive differences between these two approaches. Arithmetic combining, which tends to favor high-risk/high-gain alternatives, leads to a much more interventionist ethic than does looking at ratios. Consider, for example, two hypothetical cancer treatments: one is an experimental, high-risk/high-gain option and the other is a more standard, low-risk/low-gain alternative. Benefits and harms might be measured in hypothetical units of "utiles" or "quality-adjusted-life-years." If the experimental treatment has twice the estimated benefit and twice the estimated harm of the standard treatment, it has a larger net utility than the alternative when the harms are subtracted from benefits; however, if geometric ratios are taken as the basis for comparison, the ratios for the two treatments would be the same.

Still other forms of combining benefits and harms give special priority to considerations of nonmaleficence. For example, W. D. Ross (1930, p. 21), has argued, "It seems to me clear that non-maleficence is apprehended as a duty distinct from that of beneficence, and as a duty of a more stringent character." James F. Childress took a similar position in early editions of Principles of Biomedical Ethics (see, e.g., 1989, pp. 121-22). The famous medical moral dictum, primum non nocere, 
has coherent meaning only if it is taken to require giving first priority to not harming over doing good.

It is very puzzling what that means, however. Absolute priority for not harming is implausible. One could lock oneself in the closet and always avoid harming, but that would be an absurdly conservative ethic. On the other hand, if the dictum is taken to mean "partial priority," that is an ambiguous concept, the meaning of which is hard to envision. For example, one might in one's imagination quantify the amount of good and the amount of harm envisioned in an action and then multiply harms by some factor. A rule, "all harms count double," would be an example, but it is not clear how one would go about picking a multiplier. Why not triple or quadruple the weight given to the harms? In any case, it is clear that if the benefits were sufficiently large they would eventually overpower the harms, no matter what the multiplier. That looks less and less like making not harming first priority.

\section{Nonconsequentialist Principles}

Regardless of how one resolves the problems of quantifying and assigning priority to beneficence and nonmaleficence, many normative ethical theories include principles that do not focus on maximizing consequences.

\section{Autonomy}

The principle of autonomy-sometimes more accurately called "respect for autonomy"-holds that actions or rules tend to be right insofar as they respect the autonomous decisions of others. Sometimes the concept overlaps with notions of freedom and self-determination. Robert Nozick (1974), a libertarian philosopher, holds the view that freedom is a "side constraint." Freedom constrains actions that might otherwise be justified in that they serve some other ethical principle, such as maximizing the good. This side constraint identifies times when it would be morally wrong to pursue the good because doing so would violate the freedom of others.

The bioethicist, H. Tristram Engelhardt (1986), has developed a twoprinciple theory in which autonomy-or freedom-is given priority over beneficence. For Engelhardt freedom or autonomy is a moral principle, not a value. Under his theory someone could hold that she was morally bound to respect freedom even though freedom was not actually valued. Here again, freedom is a constraint on beneficence and not merely an outcome that some people value. 
By contrast Edmund D. Pellegrino is committed to a single-principle theory in which beneficence is the only principle that is relevant to the practice of medicine (Pellegrino and Thomasma 1988). But among the goods that one is morally obliged to pursue is the good of respect for autonomy, thus, "Beneficence...includes both respect for autonomy and a benefits-to-burdens calculus about the quality of a person's life" (p. 20). Likewise, in the rule-based theory of Bernard Gert, K. Danner Clouser, and Ronald Green, there is a moral rule against violating freedom because violating freedom is perceived as a harm (Gert 1988; Clouser and Gert 1990, 1994; Green, Gert, and Clouser 1993).

The test case that ought to separate Engelhardt and Nozick from Pellegrino, Gert, Clouser, and Green is the special situation of the existentialist who finds freedom a terrible, anxiety-provoking condition that makes one miserable, but which is nevertheless one's moral duty. Bestowing freedom in this case does not result in a valued outcome, but is nevertheless one's perceived duty. If the only reason to respect autonomy or freedom is that freedom is (usually) valued, then for Pellegrino, Gert, Clouser, and Green there would be no reason to pursue it in the special case in which it is not valued; it would not be beneficent to do so. But for one who views autonomy or freedom as a moral principle that constrains beneficence, there is potentially a moral duty to promote freedom even in existentialist-type cases.

Another potential problem arises in Pellegrino's view. His theory of the good includes four levels, in which respect for autonomy, what he calls "freedom to choose," is more important than-i.e., is ranked above-pursuit of the medical good and the patient's subjective assessment of quality of life, but is subordinate to the "ultimate good" (Pellegrino and Thomasma 1988, p. 81). This rank-ordering of goods logically commits one to abandoning the lower-level good when necessary to achieve the higher, which in this case means abandoning the "good" of respect for freedom to choose in order to serve the patient's ultimate good.

\section{Respect for Persons}

Closely related to respect for autonomy is "respect for persons." It is here that the principlist camp begins to show cracks at the seams. The Belmont Report (National Commission 1978) offers a three-principle theory that uses the Kantian term: "respect for persons." It subsumes autonomy under this broader notion, but in a strange way it also subsumes the welfare of the incompetent under respect for persons. This is 
hard to defend. Autonomy may be an element of a more fundamental notion of respect for persons, but it seems that the duty to serve the welfare of the incompetent is straightforwardly a part of the duty of beneficence.

Nevertheless, if respect for persons includes autonomy, it could include other elements as well. Here I part company with Beauchamp and Childress by including principles other than autonomy as part of respect for persons. If respect for persons includes only respect for autonomy, then nonautonomous persons are left stranded. Even if Beauchamp and Childress derive the duty to keep promises and to tell the truth to autonomous persons from autonomy, surely, these duties are not limited to those who are autonomous. Respecting persons must involve more than respecting their autonomy. I suggest that at least three other principles are prima facie right-making characteristics of actions independent of whether consequences are maximized or autonomy is respected.

(1) Veracity. The obligation to speak truthfully is not limited to statements made to autonomous persons. Veracity cannot be derived exclusively from autonomy.

(2) Fidelity to promises. Likewise, the obligation to keep promises is not limited to promises made to autonomous persons. Veracity and fidelity may be additional ethical principles. They are treated as such by W. D. Ross (1930)—assuming his "prima facie duties" are more or less synonymous with what we now call prima facie principles-and I treated them that way in $A$ Theory of Medical Ethics (Veatch 1981). I am now more inclined to see veracity and fidelity as well as respect for autonomy as components of the overarching principle of respect for persons.

(3) Avoidance of killing. There is still another possible component of respect for persons. Other things being equal, many people in many different traditions-Kant, for example-hold that killing another being is a morally wrong-making characteristic of an action. This applies at least to all human beings and perhaps to some animal species as well.

Respect for persons may include some additional principles that do not focus on maximizing consequences. For example, W. D. Ross (1930) includes gratitude for previous kindnesses of another and reparation for previous wrongs one has inflicted. All of these principles generally fall 
under the rubric of respect for persons. They do not dwell on the mere maximizing of aggregate net consequences.

\section{Justice}

Just as the principles grouped under the rubric of respect for persons provide an alternative to consequence-maximizing Hippocratic beneficence at the level of the individual, so it is possible that there is an nonconsequence-maximizing principle at the social level that provides a moral alternative to social beneficence and nonmaleficence. "Justice" is also social in character; however, rather than focusing on the mere maximization of good consequences, it focuses on the pattern of distribution.

Just as there are many interpretations of the principle of utility, so there are many versions of the principle of justice. One version, which is sometimes called the "maximin," maintains that a distribution is just only insofar as inequalities redound to the benefit of the least well off. The Rawlsian difference principle provides the most well-known example of the maximin (Rawls 1971). A second version of the principle of justice, called true egalitarianism, holds that distributions are just insofar as they distribute the goods more equally (see Veatch 1986).

The ethics of allocating scarce cadaver kidneys for transplant provides a good illustration of the difference between these distributive principles. For utilitarians the goal of allocating scarce resources is to produce the greatest possible aggregate net good. One way to accomplish this goal in organ allocation is to do histocompatibility tissue typing. We know that a "full-house" six-antigen tissue match will give a marginal predicted advantage in both graft and patient survival.

There is a problem, however. People have different probabilities of matching the donor pool. In particular, Caucasians statistically have a better chance of matching so they would have a predetermined better likelihood than other races of getting organs and thereby surviving. Defenders of justice argue that fairness requires that if we are to expect racial and ethnic minorities to contribute to the organ pool, then persons from those groups should have the same chance of benefitting from organ transplantation and should not be discriminated against in the organ allocation formula. First-come, first-served would be much fairer even though the kidney allocation system as a whole would provide slightly fewer total life years from the resources.

The United Network for Organ Sharing (UNOS) Ethics Committee confronted this question explicitly (Burdick, Turcotte, and Veatch 1992). 
Some utilitarians wanted to maximize the number of years of graft survival. Egalitarians wanted to ensure that each person with equal need had an equal shot at getting an organ. The resolution depends on how one balances social utility and justice. The committee members made a political deal that served as a solution to the problem of balancing competing ethical principles. Organs are allocated on a point system. At the time, two-thirds of the points in the formula were included because they predicted benefit to patients from HLA (histocompatibility) tissue matching. One-third were included to provide greater equity. The committee agreed to the compromise position that equal numbers of points should be included for utility and equity. Since then, the UNOS Board of Governors has adjusted the allocation formula to give somewhat better access for blacks and other minorities (Point Change 1994).

Even the conflict over the maximin and true egalitarian principles of justice has relevance to organ allocation. On occasion family members of deceased potential organ sources are willing to donate the organs, but only to certain social groups, such as members of a particular race or gender or religious affiliation. This practice of directed donation has the effect of pulling someone with the proper social characteristics out of the waiting list discriminatorily and giving him or her an advantage. Everyone seems to agree that for both utilitarian and equity reasons, it would be better if this did not happen, but, if directed donation is the only way in which to get the organs, both utilitarians and maximin theorists have supported a policy of tolerating donation directed to social classes. Utilitarians support it because the organs would otherwise go to waste. Maximin theorists support it because everyone lower on the waiting list moves up one place, thereby making the worst off better off. On the other hand, true egalitarians-whose objective is to achieve greater equality of treatment-oppose directed donation in principle. The UNOS Ethics Committee and at least one local organ procurement organization have adopted policies opposing donation directed to social groups, thus implying a true egalitarian commitment. All of these policy problems raise questions about how conflicts among ethical principles ought to be resolved.

\section{RECONCILING CONFLICTS}

\section{Single-Principle Theories}

The simplest answer to the problem of conflicting principles is to hold to a single principle. Several versions of single-principle theories exist. 


\section{Pure Libertarianism}

One approach maintains that only the principle of autonomy is morally right-making. Pure libertarianism recognizes that the only moral duty is to respect the autonomy of others. Presumably, autonomous persons are permitted to make promises, contracts, and agreements and are morally bound by their agreements. Some libertarian theories parlay this social contract into a complex system of agreements that begins to resemble some aspects of the common morality. The starting point is respect for individual autonomy. However, this univocal focus on autonomy as the only morally relevant fundamental principle has been hard to defend. Even Engelhardt (1986), whose theory relies primarily on autonomy, recognizes the need to include considerations of beneficence within moral communities.

\section{Pure Utilitarianism}

A more common single-principle approach identifies utility-some defensible combination of beneficence and nonmaleficence-as the only prir.ciple. This approach gets one much further, especially if one adopts a rule-version of utilitarianism, which permits derivative rules such as veracity, promise keeping, and justice to play a prominent role in day-today moral decision making. Bernard Gert's rule-based theory can be understood as a single-principle theory in which all the moral rules are derived from the principle of nonmaleficence (Gert 1988, p. 70).

Nevertheless, many find that the effort to treat utility as the only fundamental principle does not get one very far. Even if sophisticated versions can, with ingenuity, show how every moral judgment is compatible with a complex rule-utilitarianism, many believe that it is wrong to hold that the only reason a behavior or a rule is right is that it maximizes the aggregate net consequences. They insist that other moral principles with a different grounding must be included.

\section{Pure Hippocratism}

A variant on social utilitarianism that receives considerable attention in traditional physician ethics is pure Hippocratism, under which an action is right insofar as it produces the maximum net benefit for the individual patient. For some reason, usually unexplained, benefits and harms to any other parties do not count.

Two problems arise with single-principle theories. First, all moral choices are packed into a decision about what counts as a benefit or a 
harm (or what counts as autonomy). For example, in Hippocratism in order to decide which treatment of a patient is morally right, one must first decide whether the benefits and harms count equally and whether the goal is the total good of the patient or only the medical good. If it is the total good, it seems there is no way a physician-or anyone other than the patient-can figure out what course of action maximizes the total good for the patient since no specialized professional could be expected to have the insights necessary to know how the patient would integrate medical, legal, familial, and other goods to reach an overall maximum level of well-being. Edmund Pellegrino's beneficence, for example, packs respect for autonomy into beneficence by making such respect a value: a good to be pursued. Pellegrino's is, in effect, a singleprinciple theory in which patient-centered beneficence is the only principle.

If a patient's medical good is the only good that counts, one encounters other problems. First, there are several incommensurable medical goods including preservation of life, relief of suffering, curing of disease, and promotion of well-being. The Hippocratic consequentialist will pack all the moral judgments into figuring out what serves these ends and how conflicting ends can be reconciled. Second, no rational person wants to maximize just his or her medical good, at least if it comes at the expense of one's total well-being, which it normally would. Thus, many would insist on pursuing the total good for the patient.

Any consequence-maximizing single-principle theory transfers all of the tough decisions to questions of axiology. Any single principle, on its own, seems to leave out too much of the moral life.

\section{Balancing Theories}

If there is more than one principle, there must be some method for resolving conflict among them. The most common approach is to balance the competing principles. W. D. Ross can be considered the father of the balancers. He identifies seven "prima facie duties"-what contemporary bioethicists generally call "principles": beneficence, nonmaleficence, self-improvement, fidelity (which includes promise-keeping and veracity), justice, gratitude, and reparation. He sees no possibility of ranking these potentially competing duties, although he gives nonmaleficence a special weight. He balances the competing claims by considering the weight of each duty in a particular decision or class of decisions. There is a puzzle about how one balances these duties while giving non- 
maleficence special weight-would one count it double compared to other duties or what?-but somehow one reaches a "duty proper." Beauchamp and Childress use a similar approach to balance competing principles in their four-principle version of the mantra.

There are two problems with the balancing approach. First, historically, balancing is connected to intuitionism. It can be argued that a balancing theory is nothing more than an elaborate rationale for letting preconceived prejudices rise to the surface. One can always argue that one principle or another is more weighty. There seems to be no definitive way to reach closure. Thus, the approach fails to resolve conflicts, and it can justify any conceivable view.

Second, the balancing approach has strongly counter-intuitive implications. For example, should medical investigators be permitted to conduct dangerous medical research on a patient without the patient's consent or even against the patient's active objection? Balancers would consider the benefits to society and the harms-as well as the benefits-to the subject. They would also consider the violation of subject's autonomy as well as any promises made and the duty to avoid killing. Finally, after considering the implications of all of the principles, they would balance the competing claims. In most cases, balancers likely would conclude that the combination of risks to the subject and the violation of autonomy outweighs the benefits to others thus making forced participation in research unethical. However, the benefits to society could be very large. Indeed, if they get large enough, research against the patient's consent would be justified. That conclusion is counter intuitive or at least violates the now-well-established rule against conscription into medical research. A flat prohibition on it exists in American law. Rulebased theories claim one must balance all the applicable principles in choosing a rule about research without consent. One might choose a rule that flatly prohibits research without consent, but with a balancing' theory, one is always exposed to the claim that the rule permitting exceptions to the consent requirement wins out in the balancing contest.

Consider a second example. Should competent patients be able to refuse medical treatment that is offered for their own good? In U.S. law, no competent patient has ever been forced to undergo medical treatment offered for the patient's own good. Many people hold that this result reflects a sound moral conclusion. In this case, it seems as if autonomy always trumps Hippocratic beneficence. Balancing theorists reject this outcome in principle. They must remain committed to the notion that, 
in principle, more good would be served with a rule that forced treatment against consent in certain cases and that the good is sufficient to outweigh the violation of autonomy.

\section{Conflicting Appeals Theories}

Baruch Brody, in his Life and Death Decision Making (1988), offers a blistering attack on balancing theories. The core of his objection is that balancing implies an ability to quantify the moral weight based on each principle, which he finds totally unrealistic. He proposes a "conflicting appeals approach" in which many different moral appeals may conflict with each other to which the parties involved must respond. However, his approach is still an intuitive comparison of the power or importance of the competing principles. Aside from eliminating the metaphors of quantification implied (metaphors having to do with balancing, weighing, and the like), all the problems remain.

\section{Lexical Ordering}

The only other possibility for resolving conflicts among principles is to attempt to rank-order them by assigning each a priority so that one principle must be completely satisfied before another is allowed to come into play. Since this is analogous to the ordering of a lexicon, it is frequently referred to as lexical ordering.

A current resurgence of interest in efforts to rank principles in order of priority was stimulated by John Rawls's claim that there is a rank order to the three elements of the principle of justice. The element that requires equal liberty compatible with like-liberty for all must be satisfied before the other elements are considered. Then the principle of equality of opportunity is rank-ordered over the difference principle, which states equalities are to be arranged so as to redound to the benefit of the worst off. Less is made of it, but Rawls can also be seen as lexically ordering justice over utility.

Engelhardt (1986), who offers essentially a two-principle theory with autonomy given priority over beneficence, provides another example of lexical ordering. He mentions justice occasionally, but such references are essentially an elaboration of beneficence, rather than an independent principle of distribution.

No one has ever successfully extended lexical ordering to a ranking of all of the principles. For example, in a four-principle theory, no one has ever successfully ranked the four principles so that the first must be com- 
pletely satisfied before the second, the second before the third, and so on. Such ranking is generally believed implausible, but some combination of the approaches summarized thus far might be possible if one wants to resolve the problem of conflict among principles. This combination of approaches might include some limited lexical ranking.

\section{Mixed Strategies}

In resolving conflicts among principles, pure balancing seems too lax by permitting just about any outcome, but pure lexical ordering appears too confining. I and others have proposed that a combination of the two strategies offers a more successful solution.

\section{Talmudic Ethics}

Talmudic ethics identifies certain obligations that always have priority in Jewish law, specifically, laws that proscribe idolatry, murder, and certain sexual offenses. The law requiring preservation of life takes next priority requiring suspension of even dietary laws and laws proscribing travel on the Sabbath (Rosner and Bleich 1979, p. 19). Thus certain laws are always lexically ranked above others even though within groups a balancing of competing claims may still take place.

\section{A Modern, Secular, Mixed Approach}

I have proposed another form of a mixed approach, one that requires several steps (Veatch 1981; see Figure 1). First, balance the consequencemaximizing principles, beneficence and nonmaleficence, giving them equal weight. Then balance the nonconsequentialist principles, likewise giving them equal weight. (Should one prefer the language of reconciling conflicting appeals in order to avoid the quantification imagery, that is fine.) Third, and most critically, lexically rank the aggregate effect of the nonconsequentialist principles over the consequence-maximizing ones. This treats beneficence as an imperfect obligation. One is never obliged by beneficence to do a specific good and must refrain from doing so when a specific nonconsequentialist imperative requires it. (This position is strikingly similar to the conclusions reached by Gert (1988) except that, for Gert, beneficence is a mere ideal whereas here beneficence is a duty provided it is not superseded by non-consequence-maximizing duties. But in this approach, contrary to Gert's, other principles are not grounded in nonmaleficence and nonmaleficence is subordinated to other nonconsequentialist principles just as beneficence is.) Beneficence and nonmaleficence by themselves can never justify breaking a promise, 
Figure 1. MAJOR PRINCIPLES IN MEDICAL ETHICS

Consequence

Maximizing Principles

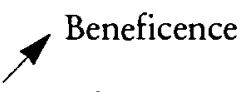

Individual

Hippocratic

Utility

Nonmaleficence

Beneficence

Social
Social

Utility
Principles Based on

Obligations Rather Than

Consequence Maximizing

Respect for Persons

Autonomy

Veracity

Fidelity

Avoidance of Killing

Justice

Nonmaleficence

Resolution of Conflict Among Principles: Balance competing claims among principles in left-hand column and competing claims among principles in the right-hand column, then lexically rank the right-hand column over the left-hand one.

telling a lie, violating autonomy, killing another, or distributing goods unjustly. Each of these must be satisfied first. There may appear to be implausible implications of this ranking. For example it may appear to require keeping a promise to meet a friend for tennis even though by breaking the promise one could rescue someone from a burning building (which seems like an act of beneficence, which must be subordinated according to the proposal). However, a robust principle of justice may also require rescuing the victim, who is clearly much worse off than the tennis player. Thus justice, which can be balanced against promise-keeping provides a basis for breaking the promise even though beneficence does not. (By contrast doing a similar quantity of good for someone who is much better off than the tennis player would not justify breaking the promise even though more good could be done.) Nonconsequentialist obligations are perfect obligations. We are generally capable of fully satisfying their requirements except when two of the perfect obligations come into direct conflict. Then we balance within this group. 
There are two instances in which beneficence and nonmaleficence come into play: when perfect obligations are fully satisfied, which happens a lot of the time, and as a tie breaker. I know of no case in modern Western ethics where utility alone justifies violating a nonconsequentialist principle. The exceptionless right of competent patients to refuse treatment only makes sense if autonomy has absolute priority over beneficence. Similarly, our standard moral judgments about research on human subjects are only intelligible if some mixed strategy of this sort is employed.

\section{An Extended Example}

To test the various approaches to conflict resolution among ethical principles consider the question of whether it is ethical to conduct an important research project on a human subject when that subject actively refuses to participate.

\section{Hippocratic Ethic}

One striking conclusion is that under the Hippocratic ethic all research on human subjects is always immoral, at least when it is designed to produce generalizable knowledge and not merely to provide the best possible innovative therapy for a patient. This is because the Hippocratic ethic requires action always only to benefit the patient and research that cannot benefit the patient is necessarily proscribed.

\section{Utilitarianism}

According to social utilitarianism, forcing a subject into research is acceptable whenever the good done predictably will exceed the harm to the unwilling subject-taking into account both the subtle harms, including psychological stress, to the unwilling subject and the harms to the practice of medical research, such as bad publicity.

\section{Balancing Theories}

Use of a balancing theory makes it more difficult to justify research without consent than is the case with utilitarianism. The principle of autonomy must be balanced against beneficence and nonmaleficence. Still, in principle, conscription of subjects is moral in cases where utility outweighs respect for autonomy.

\section{A Mixed Theory}

According to the mixed approach I have proposed, aggregate social good by itself can never justify research on a competent patient against 
his or her consent. It always violates autonomy, which takes priority over the mere production of aggregate good results for the society. On the other hand, other nonconsequentialist principles can, in principle, provide for the exceptional case in which autonomy may be overruled. Appeals to these other nonconsequentialist principles are on a par with appeals to respect for autonomy. What nonconsequentialist appeals could be entertained?

A promise of patient (later retracted). Consider a person who promises to be a subject and later unilaterally retracts the promise. In this case, there is a potential conflict between the principles of autonomy and promise keeping assuming that unilaterally retracted promises leave a residual of moral obligation. Even here, however, the two conflicting principles are on a par. It is quite possible that the duty to respect autonomy would be perceived as the weightier appeal and so justify toleration of the retraction of the commitment. Current regulations that permit patients to withdraw from research seem to respect autonomy in such cases. A similar conclusion results if one assumes that all promises to participate in research carry with them an implied reservation that one may withdraw in which case no promise would be broken when an autonomous subject withdraws.

Claims of justice. If conscription into research were necessary to promote justice to the least well off-or to redistribute well-being more equally-the claims of justice would come into play in research projects that were designed to benefit the worst off or to make them more equal. In such cases, appeals to justice might legitimately be balanced against respect for autonomy. In the practical setting, such overruling of autonomy probably should require formal due process, such as an act of Congress supported by full judicial review. The forced experimentation on Desert Storm military personnel who were required to participate in investigational use of anti-biological warfare immunizations surely did not meet anything resembling the due process standards I have in mind.

In general, we need some nonconsequentialist principle to justify violations of autonomy. Likewise, in rationing health care, violations of autonomy must be grounded in something other than the mere maximization of aggregate social utility. Appeals must be made to previous promises, such as insurance agreements with exclusions accepted by subscribers, or to claims of justice by others who need the resources. This type of mixed approach to the problem of conflict among principles makes it extremely difficult, but not impossible, to justify conscription 
of unwilling research subjects. It makes it more difficult than it is within utilitarianism and more difficult than it is even using the balancing and conflicting appeals approaches, but not as difficult as it is within the Hippocratic approach or a pure libertarianism. Only when a strong appeal can be made to other nonconsequentialist principles, such as justice, can conscription into research be contemplated and then only with an adequate due process that preserves fairness.

\section{SPECIFYING/RULES/MIDDLE AXIOMS}

\section{Alternative Approaches}

Several attempts to address the problem of conflict among principles by moving to more concrete or specific maxims have been made.

\section{Specification}

An apparently new approach to the problem of resolving conflict among principles speaks of "specification" of the principles. This approach calls for specifying a more detailed content of abstract principles in the form of more specific behavior norms. The key paper is Henry S. Richardson's "Specifying Norms as a Way to Resolve Concrete Ethical Problems" (1990). David DeGrazia (1992) has applied the approach specifically to biomedical ethics.

The approach is similar to earlier efforts to identify a level of moral rules that is intermediary between abstract principles and case-by-case decisions. The moral rules of Gert and Clouser are thus similar to Richardson's specifications as are Beauchamp and Childress's rules derived from principles. Several other attempts at moving from principles to more specific rule-level formulations have been made in ethical theory prior to the emergence of specification as a way of moving from principles to more specific rule-level formulations.

\section{Rawls: Rules of Practice}

Rawls, in his classic essay "Two Concepts of Rules," distinguished between rules that are mere summaries of moral experience-similar in some ways to the ethics of casuistry-and "rules of practice" that have a more free-standing existence that cannot be overridden by direct appeals to consequences (Rawls 1955). Nevertheless, these rules of practice may be grounded in utility or in other principles.

\section{Aiken's Four Levels of Moral Discourse}

In the 1960s an article by Henry David Aiken (1962) presented four 
levels of moral discourse: the expressive-evocative, ethical, and post-ethical levels paralleled the levels of cases, principles, and metaethical theory. Between the expressive-evocative level and the ethical, Aiken identified the moral level, sometimes referred to as the level of rules or middle axioms. James Gustafson (1966) built a classification based on Aiken that influences much theological ethics. These persistent efforts to construct a level between abstract principles and specific cases seems to be what is being undertaken again by this generation of philosophers in the specification project. Specifying principles may be a good idea whose time has come-and come again.

\section{Explication of Specifying}

Specifying involves qualifying abstract principles by "qualitatively tailoring" norms so that they provide a more specific set of moral instructions in a particular domain of case problems. Some specifications flesh out details within a single principle-e.g., beliefs about the good. For example, in medical ethics some specifications limit the relevant good to the medical sphere. In organ transplantation, to the extent that good outcomes are considered, they are limited to medically good results, and not extended to the social benefits that might result from saving certain lives. Some specifications address conflicts among principles, for example, the conflict between beneficence and autonomy in the domain of doing important but dangerous research without subject consent.

\section{What Does Specifying Imply?}

The claim of those who specify seems to imply that within limited domains, principles can be lexically ranked. If balancing were the proper approach to resolution of conflict among principles, no rule-level norm could be specified. Returning to the example of conflict between social beneficence and respect for autonomy in conducting research without consent, different research proposals would offer different potential social benefits and different degrees of autonomy violation. The balance would be different for different studies. If principles are to be balanced, no norm can successfully be specified.

Balancing theories always hold open resolution in favor of each of the principles at stake. No norm can be specified. If one of the principles at stake uniformly can take precedence over another, then specifying a rulelevel norm follows: If autonomy dominates in this domain, the follow- 
ing rule might be specified: "If a subject is substantially autonomous, always get consent before using subject in research."

In a mixed strategy, rules of practice can be articulated-or norms specified-when and only when the principles at stake can be lexically ordered. For example, autonomy always takes precedence over mere beneficence. Moreover, if one principle can be lexically ranked above another for one domain of behavior, it is hard to imagine why some other ordering could be appropriate in another domain. Rational consistency seems to require that whatever reason led one to lexically rank autonomy over beneficence in the first domain would lead to the same conclusion in other domains. But if autonomy always wins over beneficence, it still does not always win out over the nonconsequentialist principles of promise keeping, veracity, avoidance of killing, and distributing goods more equitably.

My conclusion is that the appropriate manner for the resolution of conflict among competing principles is the specification of norms in a mixed strategy that involves both some lexical ordering and some balancing. In cases of conflict, one should balance among nonconsequentialist principles and between the consequence-maximizing ones and then lexically rank the claims of the combined package of nonconsequentialist principles over the combined package of consequentialist ones.

\section{REFERENCES}

Aiken, Henry David. 1962. Levels of Moral Discourse. In Reason and Conduct, pp. 65-87. New York: Knopf.

Beauchamp, Tom L., and Childress, James F. 1989. Principles of Biomedical Ethics. 3d ed. New York: Oxford University Press.

- 1994. Principles of Biomedical Ethics. 4th ed. New York: Oxford University Press.

Brody, Baruch. 1988. Life and Death Decision Making. New York: Oxford University Press.

Burdick, James F.; Turcotte, Jeremiah G.; and Veatch, Robert M. 1992. General Principles for Allocating Human Organs and Tissues. Transplantation Proceedings 24: 2226-35.

Clouser, K. Danner; and Gert, Bernard. 1990. A Critique of Principlism. Journal of Medicine and Philosophy 15: 219-36. 
1994. Morality vs. Principlism. In Principles of Health Care Ethics, ed.

Raanan Gillon, pp. 251-65. New York: John Wiley and Sons.

DeGrazia, David. 1992. Moving Forward in Bioethical Theory: Theories,

Cases, and Specified Principlism. Journal of Medicine and Philosophy 17: 511-39.

Engelhardt, H. Tristram. 1986. The Foundations of Bioethics. New York: Oxford University Press.

Gert, Bernard. 1988. Morality: A New Justification of the Moral Rules. New York: Oxford University Press.

Green, Ronald M.; Gert, Bernard; and Clouser, K. Danner. The Method of Public Morality Versus The Method of Principlism. Journal of Medicine and Philosophy 18: 477-89.

Gustafson, James M. 1966. Context Versus Principles: A Misplaced Debate in Christian Ethics. In New Theology No. 3, ed. Martin E. Marty and Dean G. Peerman, pp. 69-102. New York: Macmillan. [Reprinted from Harvard Theological Review, April 1965].

National Commission for the Protection of Human Subjects of Biomedical and Behavioral Research. 1978. The Belmont Report: Ethical Principles and Guidelines for the Protection of Human Subjects of Research. DHEW Publication No. (OS) 78-0012. Washington, DC: U.S. Government Printing Office.

Nozick, Robert. 1974. Anarchy, State, and Utopia. New York: Basic Books. Pellegrino, Edmund D., and Thomasma, David C. 1988. For the Patient's Good: The Restoration of Beneficence in Health Care. New York: Oxford University Press.

Point Change Results from UNOS Study. 1994. UNOS Update 10 (12): 18.

Rawls, John. 1955. Two Concepts of Rules. The Philosophical Review 44: 332.

- 1971. A Theory of Justice. Cambridge, MA: Harvard University Press. Richardson, Henry S. 1990. Specifying Norms as a Way to Resolve Concrete Ethical Problems. Philosophy and Public Affairs 19: 279-310.

Rosner, Fred, and Bleich, J. David, eds. 1979. Jewish Bioethics. New York: Sanhedrin Press.

Ross, W. D. 1930. The Right and the Good. Oxford: Oxford University Press. Veatch, Robert M. 1981. A Theory of Medical Ethics. New York: Basic Books. - 1986. The Foundations of Justice: Why the Retarded and the Rest of Us Have Claims to Equality. New York: Oxford University Press. 